\title{
Percepção socioambiental: a visão de turistas e gestores de hotéis sobre os impactos da poluição das praias no turismo do Rio de Janeiro
}

\section{Environmental awareness: the vision of tourists and managers of hotel on the impacts of pollution of beaches tourism in Rio de Janeiro}

\section{Percepción ambiental: la vista de los turistas y los gerentes de los hoteles en los impactos de la contaminación en las playas en el turismo del Río de Janeiro}

\author{
Marcelo Borges Rocha ${ }^{1}$ \\ Deborah Moraes Zouain ${ }^{2}$
}

\begin{abstract}
Resumo: $\mathrm{O}$ turismo é percebido como um fenômeno econômico, social e cultural com importantes impactos socioambientais. No caso do Brasil, o Rio de Janeiro é a cidade que mais recebe turistas estrangeiros. Entretanto suas praias enfrentam problemas por causa da poluição. Nesse contexto, a análise da percepção socioambiental de turistas e gestores de hotéis sobre a qualidade das praias cariocas constitui-se em elemento para a reflexão dos impactos ambientais e, sobretudo, para políticas públicas voltadas ao turismo. Sendo assim, o objetivo desta pesquisa foi analisar a percepção socioambiental de turistas e gestores de hotéis sobre os impactos da poluição das praias no turismo do Rio de Janeiro. Para tal, foram aplicados questionários semiestruturados para turistas e gestores de hotéis. Os resultados apontaram que os turistas que chegam à cidade estão mais preocupados em desfrutar as belezas e os pontos turísticos do que se informar sobre as condições ambientais do Rio de Janeiro. Foi possível perceber, ainda, que as praias influenciam fortemente a imagem que eles têm da cidade. Por esse motivo, embora a maioria deles perceba a poluição das praias, tanto pelo aspecto estético, quanto pelo da saúde pública, não compromete o interesse em visitar o Rio de Janeiro e tampouco em frequentar as praias para banho. Vale ressaltar que, mesmo em hotéis em que se desenvolvem estratégias que auxiliam a conscientização dos hóspedes, eles continuam com a percepção apenas de turistas e não buscam informar-se sobre os potenciais riscos à saúde.
\end{abstract}

Palavras-chave: Turismo. Percepção socioambiental. Poluição das praias.

Abstract: Tourism is perceived as an economic, social and cultural phenomenon with important social and environmental impacts. In Brazil, the Rio de Janeiro is a city that receives the most foreign tourists. However its beaches face problems because of pollution. In this context, analysis of the socio environmental awareness of tourists and hotel managers on the quality of Rio's beaches constitutes a factor in the reflection of environmental impacts and, above all, for public policies aimed at tourism. Thus, the objective of this research was to analyze the environmental awareness of tourists and managers of hotels on the impacts of pollution on the beaches of Rio de Janeiro tourism. To do this, they applied semi-structured questionnaires for tourists and managers of hotels. The results showed that tourists arriving in

1 Doutor em Ciências Biológicas (UFRJ), professor da Graduação e da Pós-Graduação do Centro Federal de Educação Tecnológica Celso Suckow da Fonseca - CEFET/RJ - Av. Maracanã, 229, Maracanã - 20.271-110 - Rio de Janeiro-RJ - Brasil. E-mail: rochamarcelo36@yahoo.com.br

2 Doutora em Engenharia de Produção (COPPE/UFRJ), professora da Graduação e da Pós-Graduação em Administração da Escola Brasileira de Administração Pública e Empresas da FGV-RJ — Praia de Botafogo, 190, Botafogo - 22.253-900 - Rio de Janeiro-RJ/Brasil. E-mail: deborah.zouain@fgv.br 
the city are more concerned with enjoying the beauties and the sights than to learn about the environmental conditions of Rio de Janeiro. It could be observed also that the beaches strongly influence the image they have of the city. For this reason, although most of them realize the pollution of beaches, both for aesthetics, as the public health, does not compromise the interest in visiting the Rio de Janeiro nor in attending the beaches for swimming. It is noteworthy that even in hotels that develop strategies that help educate guests, they continue with just tourists perception and do not seek to find out about potential health risks.

Keywords: Tourism. Socio environmental awareness. Pollution of beaches.

Resumen: El turismo se percibe como un fenómeno económico, social y cultural con importantes impactos sociales y ambientales. En Brasil, Río de Janeiro es una ciudad que recibe a los turistas la mayoría de los extranjeros. Sin embargo sus playas enfrentan problemas debido a la contaminación. En este contexto, el análisis de la conciencia ambiental de los turistas y los gerentes de los hoteles en la calidad de las playas de Río constituye un factor en la reflexión de los impactos ambientales $y$, sobre todo, de las políticas públicas destinadas a turismo. Por lo tanto, el objetivo de esta investigación fue analizar la conciencia ambiental de los turistas y los gerentes de los hoteles en los impactos de la contaminación en las playas de turismo de Río de Janeiro. Para ello, aplicaron cuestionarios semi-estructurados para los turistas y los gerentes de los hoteles. Los resultados mostraron que los turistas que llegan a la ciudad están más preocupados por disfrutar de las bellezas y los lugares de interés que para conocer las condiciones ambientales de Rio de Janeiro. Se pudo observar también que las playas influyen fuertemente en la imagen que tienen de la ciudad. Por esta razón, aunque la mayoría de ellos se dan cuenta de la contaminación de las playas, tanto para la estética, como la salud pública, no compromete el interés en visitar el Río de Janeiro ni en asistir a las playas para el baño. Es de destacar que incluso en hoteles que se desarrollan estrategias que ayudan a educar a los clientes, continúan con sólo turistas percepción y no tratan de averiguar acerca de los riesgos potenciales para la salud.

Palabras clave: Turismo. Conciencia socioambiental. Contaminación de las playas.

\section{INTRODUÇÃO}

Os ecossistemas aquáticos têm sido alterados de maneira expressiva em razão de múltiplos impactos ambientais resultantes de atividades antrópicas - tais como mineração; construção de barragens e represas; retificação e desvio do curso natural de rios; lançamento de efluentes domésticos e industriais não tratados; desmatamento; e exploração de recursos pesqueiros (Callisto et al., 2001). O resultado dessas alterações representa uma queda acentuada da biodiversidade aquática, em função de desestruturação do ambiente físico/químico e alterações na dinâmica e na estrutura das comunidades biológicas.

Por localizar-se em uma das regiões mais desenvolvidas do Brasil, a Baía de Guanabara tornou-se um dos ambientes estuarinos mais degradados do País (Quaresma et al., 2000), representando atualmente um ecossistema altamente urbanizado e industrializado que recebe uma carga de poluição intensa da região metropolitana da cidade do Rio de Janeiro e das municipalidades vizinhas (Meniconi, 2007).

Segundo Santi (2008), a Baía de Guanabara é a mais proeminente do Brasil. Apesar de importante histórica, econômica, cultural e cientificamente, encontra-se entre os sistemas costeiros mais degradados do País, graças às constantes alterações sofridas desde o século 19. Essa abjeção assumiu uma escala mais acentuada nas últimas décadas em função do pleno desenvolvimento urbano-industrial.

Baptista Neto et al. (2006) afirmam que a falta de planejamento para o desenvolvimento dos centros urbanos no entorno da baía levou o ambiente ao atual estágio de degradação. Des- 
preparados para receber, em um período relativamente curto de tempo, um número elevado de habitantes, os principais centros urbanos do País, num processo de explosão demográfica, cercaram-se de um imenso cinturão de pobreza, em que as áreas mais centrais e seus principais acessos tornaram-se extremamente densos (Mattos, 2002).

A maior parte das praias cariocas, por influência direta da Baía de Guanabara, está desprovida de qualquer tipo de tratamento dos resíduos lançados diretamente em suas águas. Assim, o aumento da emissão de efluentes não tratados de esgotos domésticos e industriais tem reduzido a qualidade da água dessas praias, tornando-as impróprias para o banho em boa parte do ano, e esses problemas podem trazer consequências para o homem, como aumento de doenças veiculadas ao contato com a água contaminada, contaminação química, etc.

Diante deste cenário, ratifica-se a relevância de uma gestão eficiente da zona costeira para as cidades turísticas, assim como da gestão ambiental para os processos relacionados ao sistema urbano em expansão (Silva \& Soriano-Sierra, 2015).

Com base neste contexto, a presente pesquisa analisa a percepção socioambiental de turistas e gestores de hotéis, a fim de contribuir para a discussão acerca dos impactos da poluição das praias cariocas no turismo e nas políticas públicas da cidade.

\section{PERCEPÇÃO SOCIOAMBIENTAL}

Os impactos causados pelo homem sobre o ambiente são sentidos em toda parte. A percepção da crise ambiental por segmentos populares da sociedade mostra-se na própria rotina da população, que se liga diretamente aos diversos problemas relacionados com o aumento da pobreza nesse segmento da sociedade.

Já os grupos dominantes percebem a crise de um jeito mais indireto, pois têm a possibilidade de amenizar os problemas mais de imediato, ao distinguir no que a crise ambiental afeta o processo de acumulação de capital, que resulta da queda de produtividade (Guimarães, 2007).

Entre os conceitos existentes sobre percepção socioambiental, considera-se, como principal aspecto, a relação homem-natureza, isto é, o quanto cada indivíduo conhece do próprio meio, qual bagagem traz consigo, como lida com o meio em que vive e qual sua ação para com o meio (Cunha, 2009).

Por saber da ligação que a degradação ambiental traz para o cotidiano, muitos pesquisadores começaram a investigar e estudar o comportamento humano em relação ao ambiente em que se vive (Marczwski, 2006).

A UNESCO, em 1973, ressaltou que uma das dificuldades para a proteção dos ambientes naturais está na existência de diferenças nas percepções dos valores e da importância do meio ambiente entre indivíduos de culturas diferentes ou de grupos socioeconômicos que desempenham funções distintas, no plano social desses ambientes.

Tanto os meios naturais como os construídos provocam várias percepções individuais e podem receber valores e determinados significados importantes para as vidas. Essa percepção 
individual se dá por meio dos órgãos sensoriais - visão, olfato, paladar, audição e tato - associados à atividade cerebral. Com eles se formam ideias, imagens e criações de perspectivas. Vale lembrar que as percepções variam de pessoa para pessoa por causa das diferenças de personalidades, idades, experiências, aspectos socioambientais, educação e herança biológica, entre outros aspectos (Melazo, 2005).

Assim, no final da década de 1970 e durante a década de 1980, observa-se a emergência em estudos focalizados nos aspectos subjetivos, qualitativos e apreciativos, fundamentados nas percepções de pessoas e grupos em relação à qualidade de vida e de ambientes (Guimarães, 2005).

Os estudos de percepção socioambiental são importantes para descobertas na relação homem-ambiente, quanto a expectativas, satisfações, insatisfações, julgamentos e condutas. Cada indivíduo responde ao meio ambiente de forma diferente: essas manifestações são reflexos de processos cognitivos, expectativa de cada um e interação que cada indivíduo mantém com o meio. Com o conhecimento sobre o meio ambiente apurado pode-se interatuar da melhor forma, não causando danos a ele, o que se reflete em uma conduta preservacionista. Pode-se verificar também que cada região e/ou cada comunidade devem ser abordadas de um modo particular, pois cada uma apresenta uma realidade ambiental (Palma, 2005).

De acordo com Faggionato (2009), a percepção socioambiental pode ser definida como a tomada de consciência do ambiente pelo homem, que percebe, reage e responde diferentemente às ações sobre o ambiente em que vive. As respostas ou as manifestações daí decorrentes resultam de percepções (individuais e coletivas) dos processos cognitivos, julgamentos e expectativas de cada pessoa.

O sentimento de pertença a um lugar, construído no decurso do tempo de vida do indivíduo, acaba resultando em uma valoração sentimental do espaço, que é chamada de topofolia. Ressalte-se que a percepção do nativo sobre o seu meio é complexa e plena de valores por estar imersa na totalidade do sistema e arraigada na cultura e nos mitos locais.

Um visitante pode avaliar o espaço em função de critérios estéticos, beleza cênica, importâncias ecológica, econômica, social ou qualquer outro fator, porém sem laços de afetividade. Se, ao contrário, o sentimento em relação ao espaço for de aversão em função de alguma experiência negativa anterior, então se criará uma situação de topofobia.

Há uma contínua transformação do meio natural em zonas urbanas nas últimas décadas em razão do fenômeno de urbanização e êxodo rural. Pessoas que nascem em lugares com muitas construções e sem áreas verdes tendem a perder sensibilidade, percepção e vínculo com o meio natural, não ocorrendo, pois, a construção de uma valoração mental do meio. Portanto topofolia e topofobia são percepções opostas, já que se referem à presença de vínculo afetivo ou não entre o homem e o meio (Marczwski, 2006).

É importante lembrar que os mecanismos perceptivos são aqueles que compreendem a contribuição da inteligência, pois a mente não funciona apenas com base nos sentidos e nem recebe as sensações passivamente. Existem, por conseguinte, contribuições do sujeito ao processo 
perceptivo, incluindo motivações, humores, necessidades, conhecimentos prévios, valores, julgamentos e expectativas. Assim, a mente, de forma contínua, organiza e representa a realidade percebida por meio de esquemas perceptivos e imagens mentais, com atributos específicos (Marczwski, ob. cit.).

Portanto, além dos sentidos, atinge-se a percepção ao uni-la ao processo ativo da mente, ou seja, há uma participação da inteligência que é motivada pelos valores éticos, morais, culturais, julgamentos, expectativas e memória daqueles que o observam (Melazo, 2005).

No Brasil, a pesquisa em percepção socioambiental vem ganhando espaço nos meios acadêmico e empresarial e nas instituições envolvidas na elaboração de políticas públicas. Vale destacar o Núcleo de Estudos em Percepção Ambiental (NEPA), em Vitória-ES, além de pesquisas vinculadas às principais instituições brasileiras.

No Núcleo, criado em 2003, busca-se conhecer, em diferentes segmentos socioeconômicos, a percepção quanto ao meio ambiente, a fim de saber e quantificar a relação do homem com o meio e de como eles interagem (Fernandes, 2008).

A percepção socioambiental, usada como instrumento de educação ambiental, ajuda na defesa do meio ambiente, pois aproxima o homem da natureza - de sua verdadeira "casa" - , alerta-o sobre os cuidados e desperta nele o respeito para com o planeta. Consequentemente aumenta a qualidade de vida para as hodiernas e as futuras gerações. Dessa forma, educação e percepção ambiental surgem como importantes ferramentas para a defesa do meio natural, e contribuem para o processo de reaproximação do homem com a natureza. Segundo Santos et al. (2003), a avaliação da percepção socioambiental tem-se mostrado uma importante ferramenta na tomada de decisões quanto à gestão de praias e, ainda, na elaboração de programas voltados para a educação ambiental, contribuindo, assim, para a redução dos problemas ambientais.

\section{O TURISMO NO RIO DE JANEIRO}

Segundo Jarvis (2015), o turismo é fundamental para a economia de diversas regiões, embora em algumas partes do mundo o número de visitantes encontra-se estagnado. Sendo assim, observa-se que a satisfação do turista para a promoção do turismo nas grandes cidades tem acarretado um crescimento substancial nos estudos que se voltam para a analise da percepção dos turistas (Sarra et al, 2015). De acordo com Marujo \& carvalho (2010) o turismo pode ser considerado um fenômeno não só na esfera econômica, mas também política, sociocultural e ambiental.

Segundo dados do Boletim de Desempenho Econômico do Turismo (2015) os gastos dos turistas estrangeiros em visita ao Brasil referente ao primeiro trimestre de 2015 somaram US\$ 1637 milhões. Em outra pesquisa, o Ministério do Turismo (2015) sondou a intenção de viagem para destinos nacionais e cerca de $70 \%$ dos entrevistados afirmou que irão visitar alguma cidade turística dentro do Brasil, ficando a região sudeste em segundo lugar em intenção destes turistas.

O Brasil em 2014 superou a marca de 6 milhões de turistas estrangeiros. São Paulo permaneceu em primeiro lugar como a principal porta de entrada no país. O Rio de Janeiro, embora 
permanecendo em segundo lugar, registrou o maior número absoluto na entrada de estrangeiros, superando o ano de 2013 (Ministério do Turismo, 2015). Esse aumento considerável de turistas no Brasil deixa claro o impacto que o evento da Copa do Mundo trouxe para o turismo em nosso país. Em se tratando do Rio de Janeiro, percebe-se que as características típicas da cidade contribuem para uma maior divulgação entre turistas brasileiros e estrangeiros.

Além das belezas naturais - como praias e montanhas - , na cidade do Rio de Janeiro, há importante patrimônio histórico-cultural, que serve, assim, como espaço para grandes eventos, exposições internacionais, atividades de lazer e negócios durante o ano todo. Dessa forma, o Rio de Janeiro foi a cidade brasileira que mais sediou eventos internacionais no ano de 2011, o que põe a cidade em segundo lugar no ranking das Américas. Segundo dados do Ministério do Turismo (2012), entre 2008 e 2010, o Rio de Janeiro respondeu por 35\% da demanda turística internacional no Brasil e foi o local mais visitado no País, e o lazer, a principal motivação dos turistas. Assim, percebe-se que o turismo é, entre as segmentações econômicas, responsável por gerar empregos e renda, e a de maior crescimento mundial.

Destarte, com base nesse cenário, espera-se que, nos próximos anos, a demanda turística na cidade do Rio de Janeiro aumente significativamente, ao sediar as Olimpíadas em 2016 - importante evento internacional - , como já o fez na Copa do Mundo em 2014. Entretanto, apesar da potencialidade turística, a cidade e, sobretudo, as praias enfrentam sérios problemas por causa da poluição, visto que rotineiramente chegam às mídias nacional e internacional, acidentes ambientais que comprometem a qualidade dos recursos naturais.

Nesse contexto, a análise da percepção socioambiental de turistas e gestores de hotéis quanto à qualidade das praias cariocas constitui-se em elemento fundamental para a reflexão dos impactos ambientais e, sobretudo, para políticas públicas voltadas ao turismo. Dessa forma, tornase relevante investigar qual a percepção dos turistas e conhecer melhor suas motivações e expectativas em relação à cidade.

\section{CAMINHO METODOLÓGICO}

Desenvolveu-se a pesquisa em tela com base em abordagens quantitativas e qualitativas, estruturada de acordo com as seguintes etapas: a) Pesquisas bibliográficas e documentais sobre o turismo no Rio de Janeiro e sobre as temáticas de poluição ambiental e percepção socioambiental; b) Planejamento da pesquisa de campo, com base na elaboração do instrumento de pesquisa (em português, espanhol e inglês), ou seja, questionários semiestruturados aplicados entre turistas e gestores de hotéis; c) Pesquisa de campo propriamente dita realizada em hotéis, previamente contatados, em que houve aceitação em participar da pesquisa, entre setembro e dezembro de 2012. Vale destacar que se contataram noventa hotéis do Rio de Janeiro localizados na área de interesse, ou seja, nos bairros da Glória, do Catete, do Largo do Machado, do Flamengo, de Botafogo, do Leme e de Copacabana. Essa região foi delimitada em razão de as praias da zona sul da cidade receberem maior influência da baía de Guanabara e, também, por serem os locais que mais 
acolhem turistas, sobretudo o bairro de Copacabana. Entretanto, em apenas quatro hotéis, houve anuência em participar da pesquisa, possibilitando, assim, o emprego de questionários entre turistas e gestores. Aplicaram-se, pois, 138 questionários entre turistas brasileiros e estrangeiros, e somente quatro gestores responderam ao questionário. Colaboraram na pesquisa os hotéis Augusto's Paysandu, no Flamengo, Novo Mundo, no Catete, Mirador e Majestic, em Copacabana.

A Baía de Guanabara tem muitas praias: algumas nas Ilhas do Governador e de Paquetá, outras em Niterói, São Gonçalo e Magé. No Rio de Janeiro, encontram-se as praias de Ramos, do Flamengo, de Botafogo, da Urca, do Forte de São João e da Praia Vermelha. Na parte externa da baía de Guanabara encontram-se as praias do Leme e de Copacabana a oeste e, a leste, as de Piratininga e Itaipu.

As praias da Baía de Guanabara, avaliadas neste trabalho, ou seja, Flamengo, Botafogo, Urca, Vermelha, Leme e Copacabana, são importantes praias da zona sul do Rio de Janeiro, pois apresentam belas paisagens turísticas e são muito usadas para o lazer da população carioca (Fig. 1).

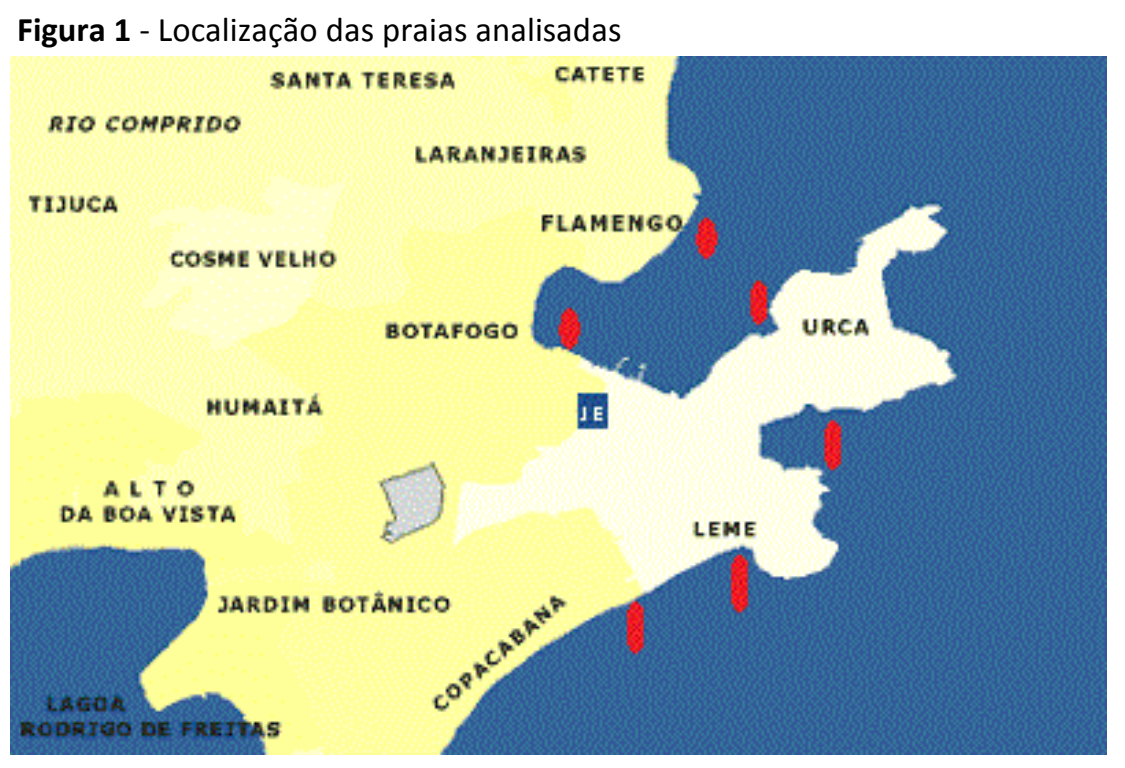

Fonte: http://www.ie.ufrj.br/pec/nukleo/img

Estruturou-se o questionário de maneira que fosse possível alcançar os objetivos da pesquisa e criar um espaço para reflexão dos participantes. Segundo Lakatos (2008), o questionário é um importante instrumento para a coleta de dados, se estruturado com base em um conjunto de perguntas que devem ser respondidas por escrito, sem a interferência do pesquisador.

O interesse em compreender os aspectos relacionados com o turismo no Rio de Janeiro na perspectiva das comunidades e instituições requer o levantamento de informações relatadas e interpretadas. Segundo Minayo (1993), os pesquisadores frequentemente se deparam com alguns obstáculos quando começam a analisar o material coletado em campo. O primeiro deles refere-se ao risco de o pesquisador estabelecer uma compreensão espontânea como se o real se lhe revelasse claramente. O segundo é o que leva o pesquisador a ceder aos métodos escolhidos, esquecendo-se do principal, ou seja, da fidedignidade das significações atribuídas ao material 
coletado.

Em razão dessas dificuldades, examinaram-se os dados à luz da análise de conteúdo (Bardin, 1977), isto é, priorizando-se o estudo dos relatos dos participantes da pesquisa sem separar o conteúdo das considerações sobre práticas, cultura e histórico no contexto das questões orientadoras da investigação.

Pela análise de conteúdo procura-se relacionar estruturas semânticas (significantes) com estruturas sociológicas (significados) dos enunciados. Articula-se, ainda, a superfície do texto descrita e analisada com os fatores determinantes de suas características, entre eles o contexto cultural e o contexto de produção da mensagem.

O procedimento de análise adotado consistiu na leitura e releitura das respostas dos questionários progressivamente, de forma a gerar interpretações pelo relacionamento entre elementos de diversos tipos, tais como a recorrência de uma palavra ou tema e seu contexto de ocorrência.

Estabelecidas essas associações, deu-se início ao processo de construção de categorias para a descrição dos dados, estabelecendo-se correspondências entre as marcas lexicais (palavras, expressões, estilos), presentes nas falas dos sujeitos, e um descritor mais geral, captor de elementos comuns a diferentes falas. Dessa forma, tornaram-se perceptíveis a importância da identificação, quão recorrentes são os termos nas falas dos participantes e os contextos que servirão de base para a construção das categorias em diversos níveis.

\section{RESULTADOS E DISCUSSÃO}

\subsection{Caracterização socioeconômica dos turistas}

No total, 138 turistas participaram da pesquisa $-50 \%$ do sexo masculino e $50 \%$ do sexo feminino. Quanto ao grau de instrução, 79\% tinham nível superior completo e $21 \%$, nível médio. Em relação à faixa etária, 28\% estavam entre 18 e 25 anos, $42 \%$ entre 26 e quarenta anos, 23\% entre 41 e sessenta anos e apenas $7 \%$ acima de sessenta anos. Dos turistas que responderam ao questionário, $70 \%$ eram de origem nacional e 30\%, internacional. Em relação aos motivos para virem ao Rio de Janeiro, $62 \%$ responderam que para fins turísticos, $24 \%$ para trabalho e $14 \%$ por outros motivos, como para visitar familiares.

\subsection{Percepção ambiental sobre a qualidade ambiental das praias do Rio de Janeiro}

No questionário aplicado, encontram-se alguns padrões de respostas. Na primeira questão, em que se indagava qual imagem ou característica era mais marcante no Rio de Janeiro, buscavase investigar a representatividade das praias para o turismo na cidade. No resultado, observou-se que $30 \%$ dos respondentes consideraram que as praias são as que melhor representam a cidade; estão atrás, apenas, do Corcovado e à frente do Pão de Açúcar (Figura 1). 
Figura 1 - Características mais marcantes do Rio de Janeiro

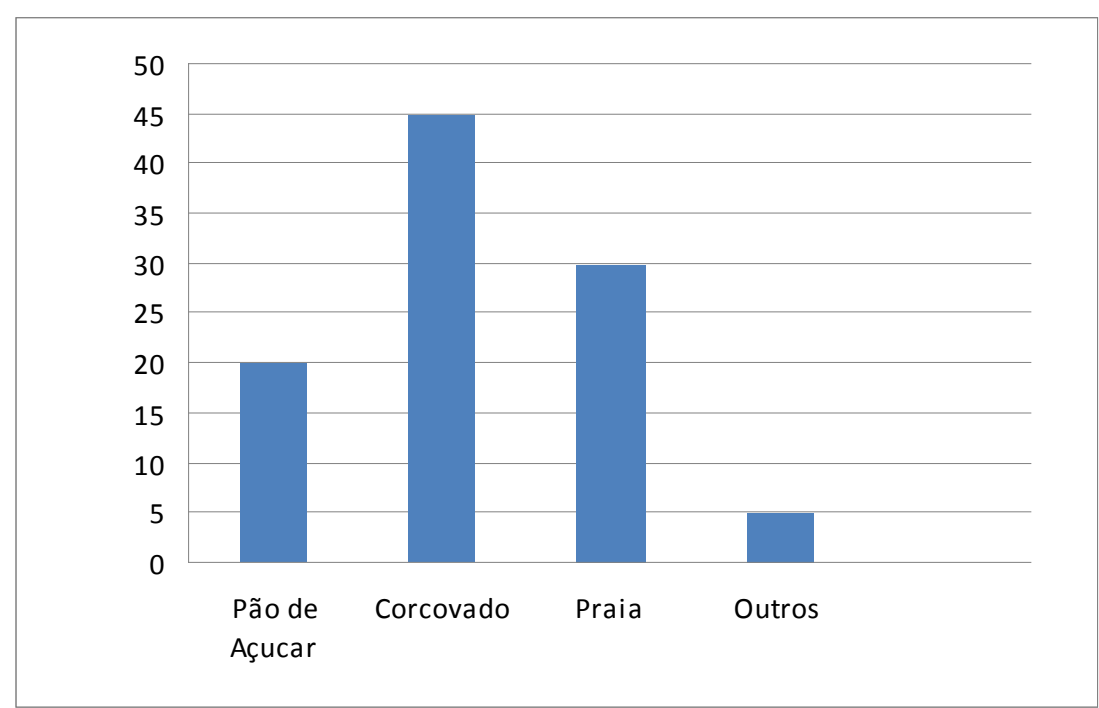

Fonte: Pesquisa

Quando questionados sobre a impressão que tiveram dos pontos turísticos visitados, incluindo as praias, $52 \%$ dos turistas afirmaram que tiveram uma boa impressão, $30 \%$, uma impressão regular, $12 \%$, uma impressão ruim e apenas $6 \%$, uma excelente impressão.

Na questão seguinte, perguntou-se aos turistas sobre a percepção que têm acerca da qualidade das praias cariocas. Surpreendentemente, a maioria deles - $67 \%$-afirmou que as praias estão limpas, $24 \%$ consideraram as praias poluídas, $8 \%$, muito limpas e apenas $1 \%$ julgou que são muito poluídas. O desconhecimento sobre os riscos da poluição marinha também foi constatado em outros estudos realizados com usuários de praias (Santos et al., 2003 e 2005). Por isso, a percepção ambiental deve ser precursora do sistema que estimule a conscientização do sujeito acerca da realidade ambiental de determinado local (Macedo, 2000).

Como forma de aprofundar a discussão acerca da poluição, perguntou-se aos turistas que tipo de poluição eles mais observaram nas praias cariocas. Como resultado, $42 \%$ afirmaram que restos de comida e objetos deixados na areia das praias mais lhes chamaram a atenção e $23 \%$ destacaram as manchas presentes na água das praias (Figura 2). Já em estudo realizado por AndradeNeto (2010) e Dias Filho et al. (2011), o plástico foi o tipo de lixo mais notado na faixa de areia. Essa dissonância de resultados pode ser explicada porque que cada indivíduo tem uma resposta diferente em relação ao meio ambiente, visto que suas percepções são reflexos de processos cognitivos diferenciados a partir da interação que cada um mantém com o ambiente (Palma, 2005). 
Figura 2 - Tipos de poluição mais observados pelos turistas nas praias cariocas

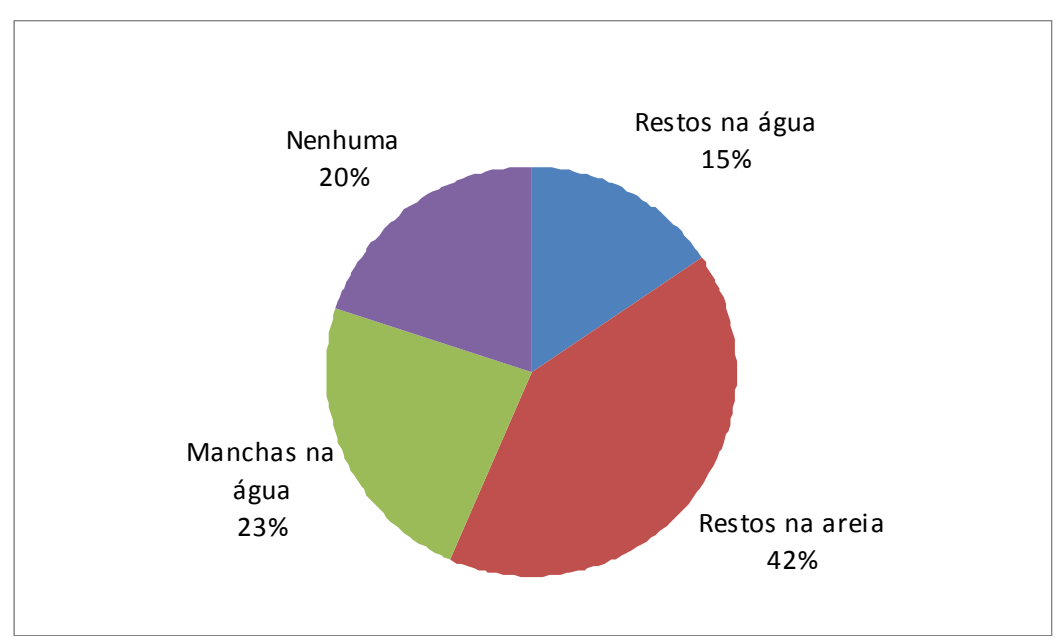

Fonte: Pesquisa

Quando perguntados se se sentem seguros para tomar banho nas praias, a maioria dos turistas - 65\% - afirmou que sim e 35\%, não. Os que não se sentem seguros, em sua maioria, justificaram que os incomodava a presença de detritos tanto na areia, quanto na água. Questionados sobre a quem caberia a manutenção da qualidade das praias, a maioria deles reconheceu que todos os usuários, banhistas ou não, devem responder pela manutenção da qualidade apropriada das praias e também atribuíram significativa responsabilidade aos órgãos públicos (Figura 3).

Figura 3 - Responsáveis pela manutenção da qualidade das praias cariocas

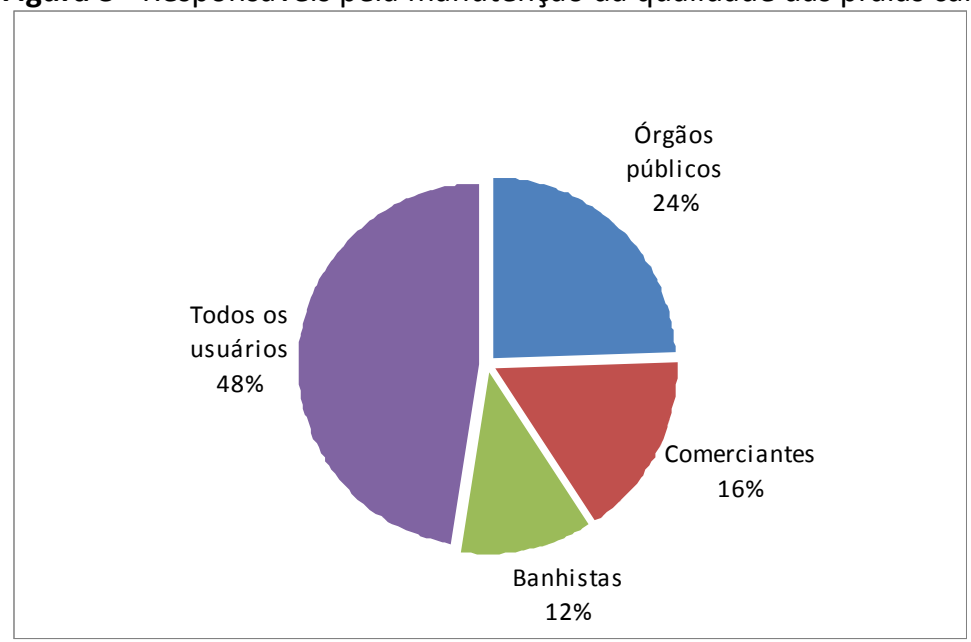

Fonte: Pesquisa

Sobre as principais consequências da poluição das praias, percebeu-se que a maioria relacionou com a contaminação da areia. Vale destacar que também sinalizaram para o fato de que a poluição das praias representa um aumento nos gastos de dinheiro público para tentar reverter esse quadro. Além disso, citaram o risco de vetores de doenças, danos aos animais e a perda estética das praias (Figura 4). Em estudo sobre a relação turismo e meio ambiente, Zi Tang (2015) observou que a qualidade ecológica de um ambiente é um dos fatores mais relevantes a serem con- 
siderados durante a elaboração de políticas públicas, devido a interferência direta na economia do turismo.

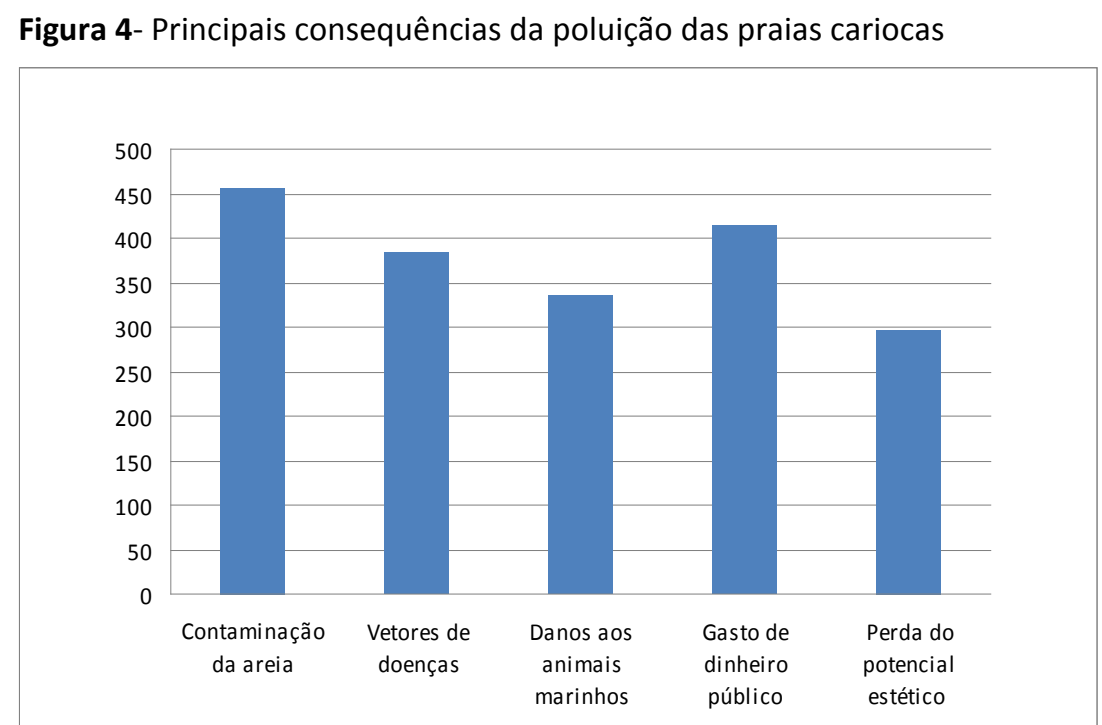

Fonte: Pesquisa

Solicitados a propor algumas soluções para o problema da poluição nas praias, $67 \%$ destacaram a importância da educação dos banhistas, que, segundo alguns turistas, precisam conscientizar-se de que não devem deixar lixos na areia porque atraem vetores biológicos causadores de várias doenças. Além disso, uma parte dos turistas que responderam a essa pergunta atentou para o papel dos órgãos públicos na manutenção da limpeza das praias.

Quando questionados sobre como lidam com os resíduos gerados durante a ida à praia, a maioria - 77\% - afirmou que descartou as sujidades em lixeiras presentes na praia, $14 \%$ levaram o lixo para o hotel e apenas 9\% não encontraram uma lixeira para descarte dos resíduos (Figura 5). De acordo com Santos et al., (2005), em geral, as pessoas atribuem a geração de lixo aos usuários, no entanto não realizam o descarte do próprio lixo na praia.

Figura 5 - Formas de descarte do lixo produzido durante passeios nas praias

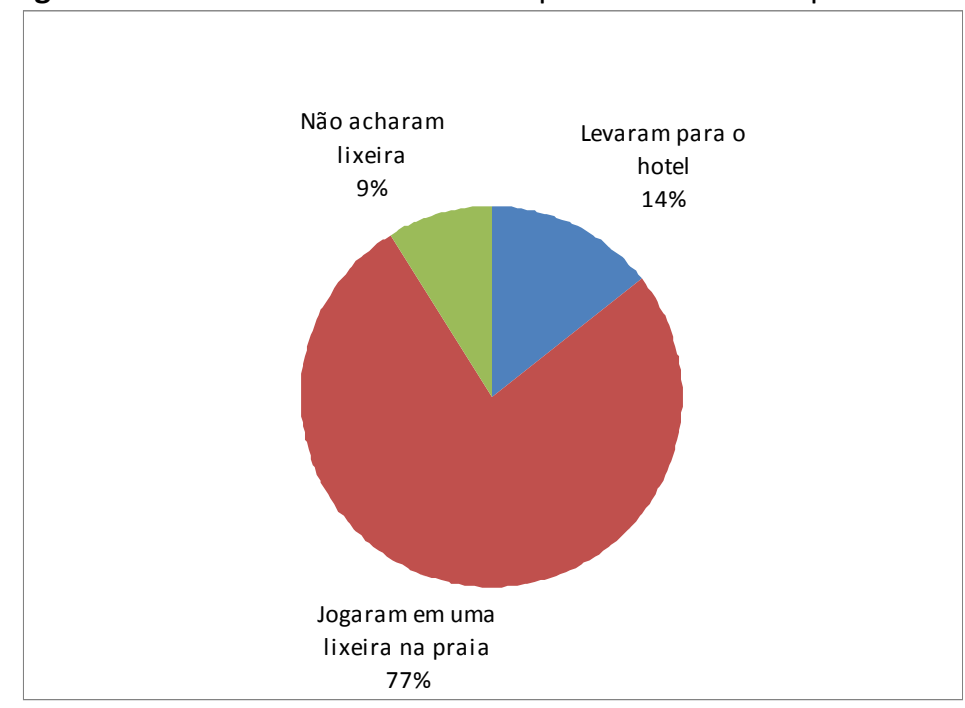

Fonte: Pesquisa 


\subsection{Caracterização dos gestores dos hotéis}

No geral, quatro gestores responderam ao questionário: $50 \%$ do sexo masculino e $50 \%$ do sexo feminino. Quanto ao grau de instrução, todos têm ensino superior completo e um deles, mestrado. Em relação à faixa etária, 75\% estão entre 41 e sessenta anos e $25 \%$ entre 26 e quarenta anos. Dos gestores que responderam ao questionário, $75 \%$ têm mais de 25 anos que atuam na rede de hotelaria e $25 \%$, menos de cinco anos. Quando questionados se já haviam participado de algum treinamento sobre programas de qualidade e meio ambiente, $75 \%$ responderam que sim e apenas $25 \%$ nunca participaram de treinamentos.

\subsection{Percepção socioambiental dos gestores}

Ao perguntar-se sobre o perfil dos hóspedes que chegam ao Rio de Janeiro, a maioria afirmou que são pessoas do segmento coorporativo: cerca de $80 \%$ são executivos e $20 \%$, turistas nacionais e internacionais. Vale destacar que se realizou a pesquisa em tela em um período de baixa temporada na cidade, visto que, em todos os hotéis que aceitaram participar, não se considerou oportuno - nem para turistas e muito menos para gestores - que fosse de janeiro a março de 2013, ou seja, nos meses de verão e carnaval em que o fluxo de visitantes é mais expressivo, uma vez que haveria sobrecarga de tarefas.

Ainda em relação ao perfil dos turistas, os gestores expuseram que a maioria se compõe de pessoas da classe média em busca de programas de turismo e fazem essa escolha por causa das belezas naturais e atrativos culturais da cidade.

Na questão seguinte, perguntou-se aos gestores se o hotel em que trabalham dispõe de algum programa que contribua para a preservação do meio ambiente e, caso tenha, qual era. Todos responderam que há a coleta seletiva e, por isso, os resíduos são separados e selecionados para posterior venda do material. Quanto ao resíduo orgânico, também é separado e recolhido pela Comlurb. Além disso, destacaram que utilizam estratégias para economizar energia, como o uso de lâmpadas mais econômicas, led em todas as áreas do hotel e sensores de presença nos corredores dos andares. E, ainda, um dos gestores acrescentou que, no hotel onde trabalha, há economizadores de água instalados em todos os chuveiros. Ressalte-se que, nesse mesmo hotel, se desenvolve um trabalho de conscientização dos hóspedes, os quais são convidados, durante a estada no hotel, a participar das medidas econômicas, desde demorar menos no banho até evitar o desperdício de energia.

Perguntou-se aos gestores se os turistas que procuram o hotel apresentam alguma preocupação com a proposta ambiental que o hotel oferece: $50 \%$ disseram que não e ressaltaram que apenas pequena parcela tem interesse em contribuir, visto que a maioria nem mesmo separa os resíduos do próprio quarto, enquanto $50 \%$ afirmaram que sim, porém os que mais apresentam esses hábitos são os turistas que visitam a cidade a negócios, como se pode ler abaixo: 
Posso the responder que sim. Ainda que um tanto incipiente e muito mais concentrada nos turistas a negócios; destes até já recebi algumas colocações com referência à economia de água e de eletricidade. No segmento de turistas a lazer realmente não vemos essa preocupação muito evidenciada. Por outro lado, a adesão na questão da lavagem das toaIhas tem sido bastante expressiva.

O outro gestor que disse sim destaca o papel do hotel em desenvolver estratégias que contribuam para a educação ambiental dos turistas, conforme mostrado a seguir:

Sim, especialmente no que diz respeito ao uso da água, temos cartazes nos apartamentos, pedindo para os hóspedes que tenham a consciência de não desperdiçar água e que evitem o desperdício de luz.

Quando questionados sobre o papel dos hotéis no processo de conscientização ambiental dos turistas que visitam a cidade, todos afirmaram que é fundamental que se desenvolva um programa eficaz de educação ambiental para os hóspedes, a fim de mostrar a importância de cuidar das próprias dependências do hotel e, também, dos espaços públicos da cidade, até mesmo das praias. Além disso, um dos gestores chamou a atenção para o papel do governo nesse processo de conscientização.

Acredito que mais do que os hotéis, o governo teria de ter maior preocupação com o ambiente; tê-lo saudável é importante principalmente para nós, moradores da cidade maravilhosa. Campanhas devem ser mais efetivas com relação a cuidados e preservação. Pensar e ser sustentável deve começar desde bem pequeno, em casa, na escola, em todos os lados por aonde vamos.

Vale destacar que outro gestor atribuiu essa função social também à entidade responsável pelos hotéis:

\begin{abstract}
Antes de mais nada, entendo que caberia aos hotéis do Rio através de sua entidade de classe a ABIH pressionarem as autoridades ambientais municipais a trabalharem objetivando proporcionar aos nossos turistas e a nossa população um ambiente turístico mais saudável em todos os níveis e locais. Aí sim, com praias limpas, sem línguas negras, com saneamento básico nas favelas, que é hoje um dos passeios mais vendidos aos turistas, nós poderíamos buscar a conscientização dos turistas para a temática ambiental. Antes de nossa própria conscientização e consequente melhora de nosso ambiente, a meu ver, se tornaria inútil e vazia nossa tentativa.
\end{abstract}

O que muito chamou a atenção nas respostas dos gestores é que um deles ressaltou que essa educação extrapola as dependências do hotel, visto que procuram orientar turistas e até os funcionários sobre a importância de procurarem a lixeira mais próxima para descarte do lixo e, assim, evitar que se polua ainda mais a cidade e, sobretudo, as paisagens naturais, como as praias. Segundo Castelli (2001, p. 73) "se a comunidade for bem preparada e conscientizada para o turismo, poderá tirar proveito tanto econômicos, como sociais", acerca da questão da importância dos valores naturais, históricos e culturas locais.

Na questão seguinte, perguntou-se se eles percebem uma preocupação dos turistas quanto à qualidade das praias cariocas. Por meio das respostas, foi possível observar que, segundo o relato dos gestores, a maioria dos turistas não se preocupa em saber como estão as condições de ba- 
nho das principais praias. Alguns até chegam a comentar que já visitaram lugares onde as praias eram mais limpas, mas parece que isso não influencia a ida ao banho nas praias cariocas. Essa ideia evidencia-se bastante na fala de um dos gestores:

Embora a praia ainda exerça um forte atrativo aos turistas que vêm ao Rio, a grande maioria sempre encontra um tempo para um banho de mar: a preocupação com o estado ambiental da praia está bem longe de ser sua preocupação. Segundo nossos recepcionistas, eles não se lembram da última vez que um turista indagou sobre o estado ambiental desta ou daquela praia. Entretanto, se perguntados, responderão em sua maioria que não confiam na qualidade de nossas areias e mares.

Ao indagar-se sobre os locais mais visitados pelos turistas que chegam à cidade, segundo a percepção dos gestores, foi possível constatar que o Corcovado é o local mais procurado, seguido do Pão de Açúcar e das praias, em terceiro lugar. Pela fala de um dos gestores, percebe-se a importância das praias para o turismo carioca:

Muitos turistas que ligam para o hotel ou mandam e-mail para fazer sua reserva, perguntam logo se o hotel fica perto da praia. Isso acontece porque nossas praias são conhecidas mundialmente e a maioria dos que chega ao Rio querem logo aproveitar o mar.

Sobre as principais consequências da poluição das praias, percebeu-se que $75 \%$ dos gestores destacaram os riscos de doenças para os usuários em razão do contato direto com a poluição e a perda do potencial estético-turístico da praia. Esse resultado chama a atenção para a divergência das respostas dos gestores e dos turistas, uma vez que, entre estes, o gasto de dinheiro público para remediar os impactos acarretados pela poluição marinha teve considerável destaque. Este fato pode ser compreendido à luz da inferência de Melazo (2005) ao dizer que as percepções podem variar de pessoa para pessoa devido a diversos fatores, dentre eles as experiências vividas, idade, personalidade, entre outras.

\section{CONSIDERAÇÕES FINAIS}

A percepção ambiental articula-se com a relação que o indivíduo tem com determinada localidade. Nesse estudo feito com turistas e gestores de hotéis no Rio de Janeiro, concluiu-se que a percepção dos turistas em relação à qualidade das praias é bastante ingênua e despreocupada. Por meio da análise das respostas dos turistas que chegam à cidade, infere-se que estão mais preocupados em desfrutar as belezas e os pontos turísticos do que se informar melhor sobre as condições ambientais do Rio de Janeiro. Diante disto, ratifica-se a importância de estudos que promovam a sensibilização e compreensão do meio ambiente a partir do desenvolvimento de um sistema de percepção junto aos turistas (Faggionato, 2009).

Foi possível observar que as praias cariocas - uma das características mais marcantes e belas do Rio de Janeiro - influenciam fortemente a imagem que os turistas têm da cidade. Por esse motivo, embora alguns percebam a poluição das praias, tanto no campo estético, quanto no 
da saúde pública, não fica comprometido o interesse em visitar o Rio de Janeiro e nem o de frequentar os espaços para banho. Tal aspecto chama a atenção, visto que muitos dos visitantes não se preocupam em saber como está a balneabilidade das praias e expõem-se a vários riscos de contaminação. Além disso, vale ressaltar que, mesmo que nos hotéis haja estratégias que auxiliem na conscientização dos hóspedes, eles continuam com a percepção apenas de turistas e não buscam informar-se sobre os potenciais riscos à saúde.

Outro aspecto que merece destaque diz respeito às iniciativas tomadas pelos hotéis que participaram da pesquisa, acerca do uso sustentável dos recursos naturais, entre eles evitar os desperdícios de energia e água. É preciso, pois, valorizar e difundir tais atitudes entre todos os hotéis. Além disso, por meio de nossos resultados, propomos que se pratiquem - na rede hoteleira e nos órgãos públicos - formas de educação ambiental a fim de divulgar e informar, de maneira mais efetiva, reais situações ambientais no estado.

Nessa perspectiva, sugere-se que essas informações sejam socializadas por meio de cursos de capacitação durante o processo de formação dos gestores e de todos os funcionários que trabalham na rede hoteleira. E mais: defende-se que os princípios básicos de sustentabilidade ambiental devam incorporar-se, também, ao contexto escolar, de forma que contribuam para a formação de indivíduos mais críticos sobre os impactos ambientais e suas consequências. Essa estratégia torna-se relevante visto que muitos usuários das praias cariocas banham-se e utilizam a areia como área de lazer sem ter em mente os possíveis riscos à saúde. Muitas vezes é possível encontrar pessoas, até mesmo crianças, que se enterram na areia de muitas praias citadas neste estudo desconsiderando a quantidade de contaminantes com que favorecem o contato com o corpo e, sobretudo, os riscos do desenvolvimento de inúmeras doenças. Cabe, assim, à escola, aos órgãos públicos e às instituições privadas difundirem e sensibilizarem a população e os visitantes acerca desses riscos.

Outro fator que merece destaque é a questão do descarte de lixo, visto que, por meio do estudo, se revela que turistas e hotéis sinalizaram para a responsabilidade ambiental que cada um tem, uma vez que a maioria dos entrevistados afirmou ter atitudes corretas em relação ao lixo que produz.

É importante destacar que, em muitos hotéis - 90\% - além da Associação de Hotéis do Rio de Janeiro, não se conseguiu autorização para a aplicação dos questionários destinados à pesquisa. Outro dado interessante, passado pelos gestores, é que muitos turistas não mostraram interesse em responder perguntas e, assim, contribuir para novas iniciativas ambientais. Espera-se que esses resultados sirvam como desdobramentos para futuros investimentos em educação e formação, nos órgãos competentes, no sentido de ampliarem-se as possibilidades de acesso a informações que, em muito, contribuirão para uma tomada de decisão mais consciente entre turistas ou gestores e funcionários dos hotéis da cidade.

$\mathrm{Na}$ intenção de proporcionar resultados práticos para o turismo no Rio de Janeiro, neste estudo, chama-se a atenção para a importância de criarem-se iniciativas e atividades a fim de contribuir para a melhoria dos resultados da atividade turística e da qualidade de vida de todos os 
frequentadores dos espaços públicos da cidade. Nesse sentido, Silva \& Soriano-Sierra (2015) apontam para a importância de uma efetiva gestão das regiões costeiras para as cidades turísticas e, ainda, destacam a expressiva contribuição da gestão ambiental para os processos decisórios dos sistemas urbanos. Assim, não basta a realização de campanhas isoladas em determinadas datas, mas a efetiva sensibilização que deve ser permanente e participativa. Além disso, o conhecimento da percepção entre turistas e gestores de hotéis no Rio de Janeiro sobre a qualidade das praias é fundamental para a elaboração do plano de gestão pública e de programas de educação ambiental.

Diante do exposto, propõe-se, como desdobramento da pesquisa, a criação de programas de educação ambiental em que se trabalhe a sensibilização dos cidadãos, tanto no que diz respeito a gestores e funcionários da rede hoteleira, quanto, a turistas que chegam ao Rio de Janeiro. Além disso, sugere-se que essas iniciativas fomentem ações em bases sustentáveis, que incluam a todos, desde o Poder Público até moradores e visitantes. Santos et al (2003), também concluíram que a percepção socioambiental dos turistas mostrou-se como um importante recurso para a elaboração de programas de educação ambiental que contribuam para a redução dos impactos ao meio ambiente.

Pelos resultados, aponta-se, ainda, a necessidade de expandir a amostragem e a discussão acerca da importância de um ambiente natural saudável para o bem-estar de todos. Sempre que se tenha, nos conhecidos cartões-postais da cidade, a oferta de segurança, lazer e entretenimento haverá incremento, no setor hoteleiro, o que, consequentemente, será convertido em benefícios econômicos para a cidade. Nesse sentido, sugerem-se novas pesquisas que envolvam gestores, turistas e Poder Público, mais especificamente os setores envolvidos na gestão do turismo e nas questões relacionadas com o meio ambiente do Rio de Janeiro.

\section{REFERÊNCIAS}

Andrade-Neto, G. F. (2010). Análise quali-quantitativa de lixo de praia com aplicação do clean-coast index em uma praia do litoral centro-sul do estado de São Paulo, Brasil. 201054 f. Trabalho de conclusão de curso (Oceanografia) - Centro Universitário Monte Serrat (Unimonte), Santos.

Baptista Neto, J. A. et. al. (2006). Spatial distribution of heavy metals in sufircial sediments from Guanabara Bay: Rio de Janeiro, Brazil. Environmental Geology, 49(6), 1.051-1.053.

Bardin, L. (1977). Análise de conteúdo. Paris: Presses Universitaires de France.

Boletim de Desempenho Econômico do Turismo. (2015). Abril, ano 12, n. 46. Disponível em: http://www.dadosefatos.turismo.gov.br/export/sites/default/dadosefatos/conjuntura economica/boletim de sempenho turismo/download boletim desempenho economico turismo/BDET 46 2.pdf. Acesso em: 22. ago. 2015.

Callisto, M.; Moretti, M.; Goulart, M. D. C. (2001). Macroinvertebrados bentônicos como ferramenta para avaliar a saúde de riachos. Revista Brasileira de Recursos Hídricos, 6(1), 71-82. 
Castelli, G. (2001). Turismo: atividade marcante. (4a ed). Rio Grande do Sul: EDUES.

Cunha, A. S. (2009). Percepção ambiental: implicações para a educação ambiental. Sinapse Ambiental, 6(1), 66-79.

Dias-Filho, M. et al. (2011). Avaliação da percepção pública na contaminação por lixo marinho de acordo com o perfil do usuário: estudo de caso em uma praia urbana no Nordeste do Brasil. Revista da Gestão Costeira Integrada, 11(1), 49-55.

Faggionato, S. (2009). Percepção ambiental. Disponível em: http://www.educar.sc.usp.br/biologia/textos/m a txt4.html. Acesso em: 14 maio de 2014.

Fernardes, R. S. (2008). Avaliação da percepção ambiental da sociedade frente ao conhecimento da legislação ambiental básica. In: ENCONTRO LATINO- AMERICANO DE UNIVERSIDADES SUSTENTÁVEIS, 1., 2008, Passo Fundo-RS Anais... Passo Fundo-RS: UPF.

Jarvis, D.; Stoeckl, N.; Jarvis, L.; Liu, B. (2015). The impact of economic, social and environmental factors on trip satisfaction and the likelihood of visitors returning. Tourism Management. Vol. 52, 1-18.

Guimarães, M. (2007). Educação ambiental: no consenso um debate?. (5a ed) Campinas-SP: Papirus. (2005). Formação de educadores ambientais. (3a ed). Campinas-SP: Papirus.

Lakatos, E. M. (2008). Metodologia do trabalho científico. (4a ed). São Paulo: Atlas.

Macedo, R. L. G. (2000). Percepção e conscientização ambiental. Lavras, MG: Editora UFLA/FAEPE, 132p.

Marczwiski, M. (2006). Avaliação da percepção ambiental em uma população de estudantes do ensino fundamental de uma escola municipal rural: um estudo de caso. 2006. 156 f. Dissertação (Mestrado em Ecologia) - Departamento de Ecologia da Universidade Federal do Rio Grande do Sul (UFRGS), Porto Alegre.

Marujo, M. N., \& Carvalho, P. (2010). Turismo, planejamento e desenvolvimento sustentável. Turismo \& Sociedade. Curitiba, 3 (2), 147-161.

Mattos, N. (2002). Perfil das ONG's ambientalistas atuantes na Baía da Guanabara, 1990-2001, RJ. 2002. 129 f. Dissertação (Mestrado em Ciência Ambiental) - Centro de Estudos Gerais do Instituto de Geociências da Universidade Federal Fluminense (UFF), Niterói-RJ.

Melazo, G. C. (2005). Percepção ambiental e educação ambiental: uma reflexão sobre as relações interpessoais e ambientais no espaço urbano. Olhares e Trilhas. Uberlândia. 6(6), 45-51.

Meniconi, M. F. G. (2007). Hidrocarbonetos policíclicos aromáticos no meio ambiente: diferenciação de fontes em sedimentos e metabólitos em bile de peixes. 2007. 192 f. Tese (Doutorado) - Centro de Ciências Exatas e da Terra da Universidade Federal do Rio Grande do Norte (UFRN), Natal-RN.

Minayo, M C. (1993). O desafio do conhecimento: pesquisa qualitativa em saúde. São Paulo: Hucitec/Abrasco. 
Ministério do Turismo. (2015). Dados e Fatos. Brasília, 2012. Disponível em: <http://www.turismo.gov.br/dadosefatos>. Acesso em: 21.ago.2015.

Palma, I. R. (2005). Análise da percepção ambiental como instrumento ao planejamento da educação ambiental. 2005. 198 f. Dissertação (Mestrado em Engenharia) - Escola de Engenharia da Universidade Federal do Rio Grande do Sul (UFRS). Porto Alegre-RS.

Quaresma, V. S; Dias, G. T. M; Baptista Neto, J. A. (2000). Caracterização da ocorrência de padrões de sonar de varredura lateral e sísmica de alta frequência $(3,5$ e 7,0 kHz) na porção sul da baía de Guanabara-RJ. Brazilian Journal of Geophysics, 18(2), 201-214.

Santi, L. (2008). Estratégia reprodutiva e dinâmica populacional de Poecilochaetus australis Nonatu, 1963 (Polychaeta, Spionidae) em local sujeito a influência de efluentes não tratados, baía de Guanabara-Rio de Janeiro/Brasil: Projeto Australis. 2008. 236 f. Dissertação (Doutorado em Oceanografia) - Instituto Oceanográfico da Universidade de São Paulo (USP), São Paulo.

Santos, I. R.; Friedrich, A. C.; Duarte, E. (2003). Percepções sobre o lixo na praia do Cassino (RS, Brasil). Mundo \& Vida, 4(1), 11-17.

; ___ Wallner, M.; Fillmann, G. (2005). Influence of socio-economic characteristics of beach users on litter generation. Ocean \& Coastal Management, 48(10), 742-752.

Sarra, A.; Zio, S.; Sarra, M.; Cappucci, M. (2015). A quantitative valuation of tourist experience in Lisbon. Annals of Tourism Research, v.53, 1-16.

Silva, M. E. M; Soriano-Sierra, E. J. (2015). Análise da percepção do visitante sobre a revitalização da orla marítima: o modelo do Parque Linear Calçadão, Itapema - Santa Catarina, Brasil. Revista Brasileira de Pesquisa em Turismo. 9(1), pp. 76-96.

Tang, Z. (2015). An integrated approach to evaluation the coupling coordination between tourism and the environment. Vol. 46, 11-19.

Artigo recebido em: 26/08/2014. Artigo aprovado em: 24/08/2015. 